Review Article

\title{
Overview of proteomics studies in obstructive sleep apnea
}

\author{
Amélia Feliciano ${ }^{\mathrm{a}, \mathrm{b}, 1}$, Vukosava Milic Torres ${ }^{\mathrm{b}, 1}$, Fátima Vaz ${ }^{\mathrm{b}}$, Ana Sofia Carvalho ${ }^{\mathrm{b}}$, \\ Rune Matthiesen ${ }^{b}$, Paula Pinto ${ }^{a}$, Atul Malhotra ${ }^{c, d}$, Cristina Bárbara ${ }^{a}$, Deborah Penque b,* \\ a Serviço de Pneumologia, Centro Hospitalar Lisboa Norte, E.P.E., Lisboa, Portugal \\ b Laboratório de Proteómica, Departamento de Genética Humana, Instituto Nacional de Saúde, Dr. Ricardo Jorge I.P., Lisboa, Portugal

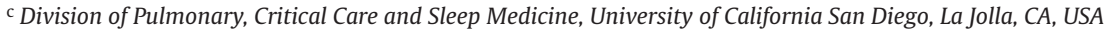 \\ d Division of Sleep Medicine Sleep Disorders Research Program Brigham E Women's Hospital and Harvard Medical School, Boston, MA, USA
}

\section{A R T I C L E I N F O}

\section{Article history:}

Received 29 May 2014

Received in revised form 25 November

2014

Accepted 27 November 2014

Available online 14 February 2015

\section{Keywords:}

Obstructive sleep apnea

Biomarkers

Proteomics

Mass spectrometry

Lung

Metabolic disorders

\begin{abstract}
A B S T R A C T
Obstructive sleep apnea (OSA) is an underdiagnosed common public health concern causing deleterious effects on metabolic and cardiovascular health. Although much has been learned regarding the pathophysiology and consequences of OSA in the past decades, the molecular mechanisms associated with such processes remain poorly defined. The advanced high-throughput proteomics-based technologies have become a fundamental approach for identifying novel disease mediators as potential diagnostic and therapeutic targets for many diseases, including OSA. Here, we briefly review OSA pathophysiology and the technological advances in proteomics and the first results of its application to address critical issues in the OSA field.
\end{abstract}

(C) 2014 Elsevier B.V. All rights reserved.

\section{Obstructive sleep apnea syndrome}

Obstructive sleep apnea (OSA) is a common sleep-related breathing disorder which is characterized by recurrent occurrence of partial or complete closure of the upper airway during sleep, despite ongoing efforts to breathe [1]. These obstructive events result in interruption of sleep with frequent arousals, loss of REM sleep and slow-wave sleep, cyclical deoxygenation/reoxygenation, and repeated changes in intrathoracic pressure with episodic hypercapnia [2-4]. Symptoms for OSA are multiple and include snoring, excessive daytime fatigue, apneas while sleeping, morning headaches, concentration problems, forgetfulness, depression, and sexual dysfunction, among others [1-3]. The majority of patients with OSA remain undiagnosed since most of them only come to the attention of a clinician when they complain of daytime sleepiness or when their bed partners report loud snoring or witnessed apnea episodes. Epidemiological studies have indicated that OSA affects $6-13 \%$

\footnotetext{
* Corresponding author. Laboratório de Proteómica, Departamento de Genética Humana, Instituto Nacional de Saúde, Dr. Ricardo Jorge I.P., Lisboa, Portugal. Tel.: +217508137 ; fax: +217526410 .

E-mail address: deborah.penque@insa.min-saude.pt (D. Penque).

1 Both authors contributed equally to this paper.
}

of the adult population [5] and 1-4\% of the pediatric population [6]. The prevalence of OSA is much higher, eg, $\geq 50 \%$, in patients with cardiac or metabolic disorders than in the general population [5]. Untreated OSA worsens quality of life and brings long-term consequences, which include cardiovascular disease hypertension, diabetes, obesity, stroke, depression, and a variety of metabolic disorders. Major risk factors that contribute to OSA pathogenesis include aging, male sex, and obesity. About $60-70 \%$ of patients with OSA are obese, and obesity is the most common metabolic disorder [7-10]. The pathophysiological mechanisms of OSA are both complex and incompletely understood, with differences between afflicted adults as compared to children. OSA is associated with adenotonsillar hypertrophy, craniofacial disorders, lymphoid tissue growth, upper airway inflammation, and/or neuromuscular factors [5,6,11].

The definitive diagnosis of OSA currently requires an overnight polysomnographic laboratory-based polysomnography (PSG), which is expensive and cumbersome [12]. Home unattended study using a portable sleep monitor has been encouraged, but $56 \%$ of these cases still require confirmation by laboratory study [13].

The presence and severity of OSA is usually based on PSG, namely by apnea-hypopnea index (AHI) (consisting of the sum of apneas and hypopneas per hour of sleep) or by the respiratory disturbance index (RDI) (consisting of the sum of apneas, hypopneas and respiratory effort related arousals per hour of sleep). Adult patients can be classified as disease free $(A H I<5 / h)$, mild $(A H I \geq 5$, but $<15 / h)$, moderate $(A H I \geq 15$, but $<30 / h)$, or severe OSA 
$(\mathrm{AHI} \geq 30 / \mathrm{h})[14]$. However, the hypopnea definition criteria are not consensual, which can result in highly variable AHI values. Consequently, potentially classifying symptomatic patients who would benefit from treatment are not meeting treatment criteria for OSA. Moreover, no current established threshold level for AHI exists that indicates the need for treatment [14-16].

The continuous positive airway pressure (CPAP) is considered the first line treatment in OSA, reducing co-morbidities and associated societal consequences such as accidents and cognitive impairment. However, residual sleepiness may persist in some patients and most chronic consequences of OSA may not be fully reversed by CPAP treatment [17-20].

Although significant progress has been made over the past few decades, OSA is still a highly underdiagnosed disorder causing deleterious effects on human health. Early identification of OSA in patients by a simple and inexpensive point-of-care screening test is urgently needed to prevent OSA consequences. To better understand the disease complexity, the molecular factors contributing to the basic mechanisms underlying OSA and OSA bidirectional association with neurocognitive and cardiometabolic dysfunctions must be elucidated. Identification of early and predictive biomarkers of OSA can be a useful tool in its global strategy, not only at the level of diagnosis, facilitating timely screening but also at the level of prognosis and therapy monitoring, contributing to a better understanding and prevention of OSA and OSA-associated disorders. 'Omics'based strategies such as proteomics have the potential to revolutionize sleep medicine and boost understanding of pathophysiological pathways of OSA. Proteomics approaches could be crucial in the identification of new OSA diagnostic and prognostic biomarkers, which could subsequently lead to the development of novel therapeutic strategies for the treatment of this disease [21].

In this review we are highlighting recent technological advances in proteomics and presenting an up-to-date overview of achievements of the proteomics approach in the study of OSA syndrome.

\section{Proteomics-based technologies}

Proteins are codified by genes to play different roles in cell/ tissue/organism (eg, cell-based structures, enzymes, signaling factors, hormones). There are, however, more proteins, probably up to one million, than their corresponding codifying genes $(20,500)$ in humans. Several proteins can be generated from only one gene by alternative splicing of RNA (the gene messenger) and after translation proteins can be modified by up to 400 types of posttranslational modifications (PTMs) (eg, phosphorylation, glycosylation, acetylation), generating different proteoforms with probably different protein-protein interactions and functions at different cellular/ tissue locations [22]. Alterations in protein sequencing (mutations in genes) but also in protein abundance and PTMs can modulate/ dysregulate its function and be associated with a disease state, drug, or environmental response.

Proteomics is a large-scale discovery strategy (see Fig. 1), which refers to the set of technologies applied to explore the proteome, allowing evaluation of hundreds to thousands of proteins at certain times and under certain conditions [23]. The benefits of proteomics are to obtain information regarding changes in protein abundance, protein proteoforms (genetics and PTMs), protein-protein interactions in a cell, tissue, or organism that can be crucial to understanding the true molecular phenotype of a disease, which may also uncover disease biomarkers and disease targets for new drug development [24].

In the last decade different proteomics-based technologies have been developed, enabling simultaneous assessment and detection of large numbers of proteins in biological samples. In disease biomarker discovery, proteomics have been popular in blood, either on plasma, serum or blood cells. Proteomics in biological fluids such as urine, bronchial lavage or aspirate, and tissues like nasal epithelia have also been considered in proteomics study diseases [25,26]. Globally, the protein profiling of biological samples using proteomic approaches is challenging due to the abundance and diversity of proteins. Proteins exhibit an enormous dynamic range of concentration in biological systems, making identification and quantification problematic especially for candidate biomarkers presented at lowabundance in a complex sample [27]. Proteins cannot be amplified as DNA prior to measurement, therefore ultrasensitive techniques are needed to measure and analyze proteins that are mostly at low concentrations in a complex mixture or when samples themselves are scarce as the clinical samples usually are.

Proteomics technologies have been in constant development. However, the most popular procedures are two-dimensional gel electrophoresis (2-D gel) and liquid chromatography (LC) for protein separation, both followed by tandem mass spectrometry (MS/MS) for protein identification (Fig. 1). For either case, proteins should be first extracted from biological samples using compatible biochemical methods, eventually involving fractionation or enrichment procedures, known by sample preparation [28].

\subsection{2-D gel approach}

In the 2-D gel approach the extracted proteins are separated by their isoelectric point (pI) (first dimension) and then by their molecular weight by sodium dodecyl sulfate-polyacrylamide gel electrophoresis (SDS-PAGE) (second dimension). After electrophoresis, gels are stained (eg, Coomassie Blue, silver staining) and the developed 2-DE pattern images showing thousands of proteins are captured by a scanner and analyzed by computer assistance for quantification. The protein spots showing significant differences (lower or higher abundance or presence or absence) between disease and control are excised from gels for further MS identification. The limitations of 2-D gel are associated with its inability to resolve all proteins present in a sample due to differences in protein solubility or hydrophobicity, wide range in protein expression levels (highversus low-abundance proteins), presence of too basic or acidic proteins that exceed the $\mathrm{pH}$ range capacity, or SDS-PAGE upper or lower molecular size gel limits. Difference gel electrophoresis (DIGE) [29] is an improved modification of 2-D gel, in which controls and diseased samples pre-labeled with different fluorescent CyDyes can be analyzed on a single gel together with an internal standard (the sum of all disease/control CyDye-labeled samples in one), reducing experimental variation and increasing sensitivity and protein detection by up to five orders of magnitude [30]. The 2-D gel patterns can be visualized for each CyDye-labeled sample (disease/control) using specific fluorescence scanners for further computer-based quantification and spot excision for MS identification (Fig. 1).

\subsection{Shotgun proteomics (LC/MS/MS)}

In shotgun proteomics, the extracted proteins are digested, typically with trypsin, and the produced peptides separated by LC such as strong anion exchange combined with reverse-phase chromatography and fractions analyzed by an online tandem mass spectrometer for peptide and protein identification (Fig. 1). Initially applied for full identification and characterization of proteomes, the shotgun approach was soon extended to quantitative and comparative studies in biomarker discovery, due to the introduction of stable isotope labeling strategies like ICATs, stable isotope labeling with amino acids in cell culture (SILAC), and more recently, isobaric tags such as iTRAQ and tandem mass tags (TMT) for relative and absolute quantification [28]. In brief, these reagents use 'tags' of different masses to label differentially proteins from control or disease proteins, which are then pooled and analyzed via MS to 

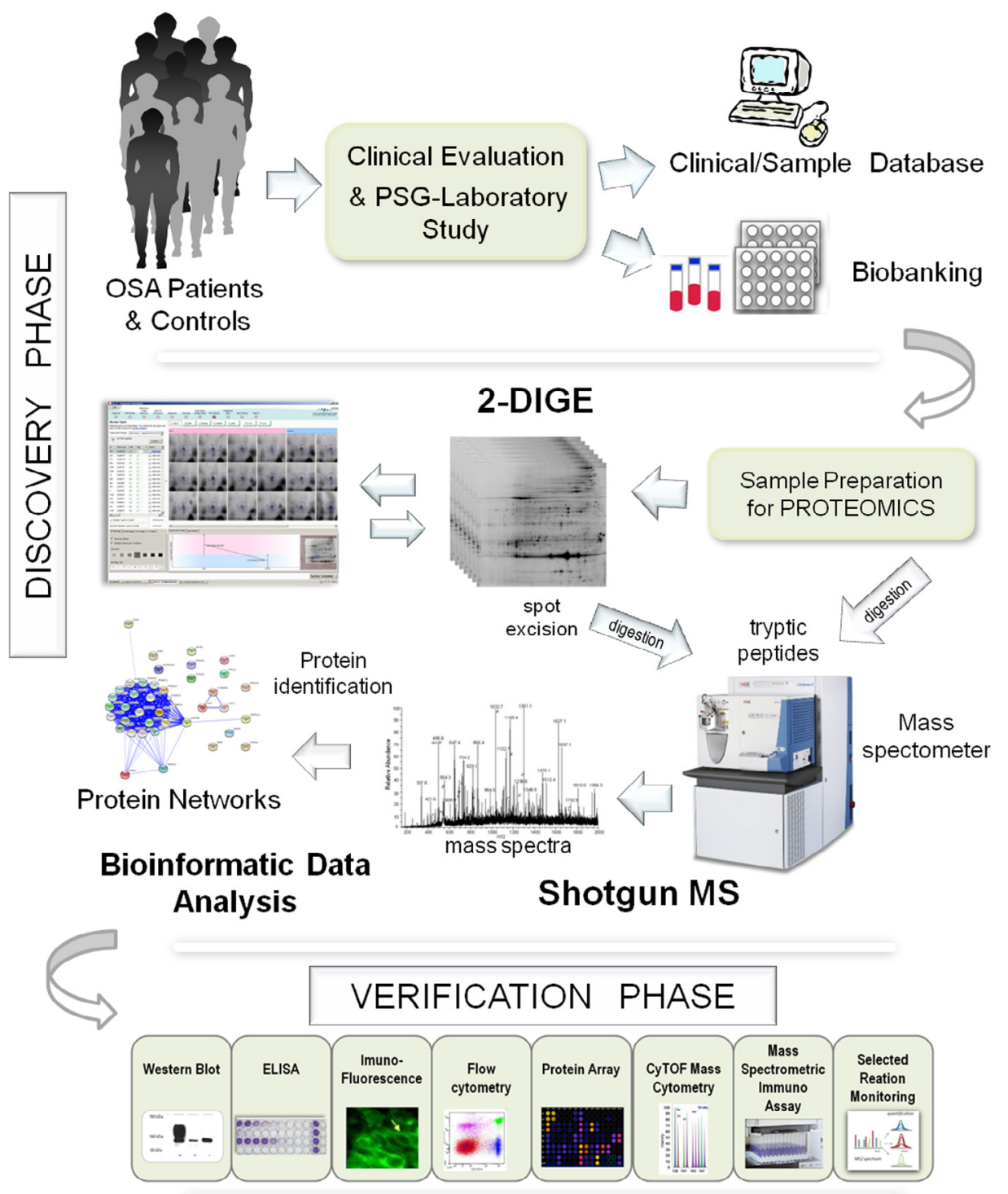

\section{CANDITATES BIORMAKERS OF OSA}

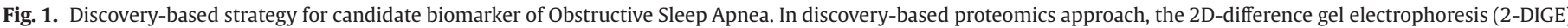

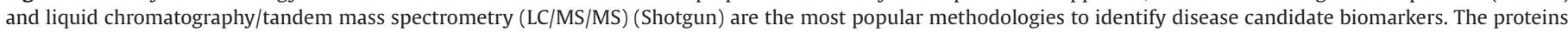

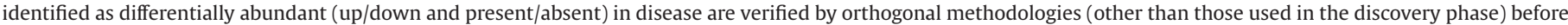
proceeding to the next validation phase in a larger cohort of patients and translation into clinical application.

identify and quantify peptides and hence proteins. Multiplexed analysis allowing differentially labeled samples being simultaneously measured by MS is the main advantage of these stable-isotopelabeled methods. The limitations are related to incomplete labeling, variability in chromatographic runs, complex sample preparation, need for a higher protein concentration and, not least, higher costs. Due to these shortcomings, label-free quantitative proteomics have become an attractive method. This is usually based on a spectral counting approach, which implies a counting and comparison of the number of fragment-ion spectra (MS/MS) acquired for pipettes of a given protein based on the empiric observation that higher abundance of a particular protein in a sample is related to higher number of corresponding peptides MS/MS spectra [31,32]. Although label or label-free LC-MS/MS methods still suffer from some issues with reproducibility and dynamic range, these methods have been shown to provide increased proteome coverage compared to 2-D gels. Nevertheless, comparative studies between 2DE-MS and LC-MS/MS have shown limited overlapping among proteome identifications suggesting the complementary nature of these approaches [33].

Although less popular than the 2D-gel or LC/MS/MS approaches, surface enhancer laser desorption ionization time of flight MS technology (SELDI-TOF) and capillary electrophoresis coupled MS (CEMS) have been also used for disease biomarker discovery, including OSA.

\subsection{SELDI-TOF}

SELDI-TOF combines retention of proteins by adsorption or affinity chromatography on a solid-phase protein chip surface that can be further analyzed by MS. Initially, this technology only 
provided MS spectra profiling without protein identification. New ProteinChip interface coupled to tandem mass spectrometer was recently developed allowing direct sequencing of peptides $<6000 \mathrm{Da}$. However, further confirmation by antibody-based methods (ie, western blot or ELISA) or antibody pull-down with subsequent detection by SELDI-TOF-MS is still recommended [34] for confident protein identification.

\section{4. $C E-M S$}

In CE-MS, instead of separations by LC, protein extracts, usually body fluids, are separated by CE prior to MS identification. Although interfaced with MS, direct protein sequencing could be a challenge due to limited loading capacity of the CE [35].

\subsection{Target proteomics}

In contrast to those above technologies which operate on an unbiased mode discovering what proteins can be detected and quantified in a sample, an alternative method, known as target proteomics, has been developed as a biased approach testing whether a given protein or a set of proteins is measurable in a particular sample [36-38]. This target proteomics is based on the selectedor multiple-reaction-monitoring (SRM/MRM) technology, in which the mass spectrometer is programmed to pre-select and analyze specific peptides generated from proteins of interest. This requires that relevant proteins for a given sample or disease be determined a priori, which can be a limitation for biomarker discovery studies. Target proteomics has been used very successfully for verification/ validation of the data obtained in the discovery phase (see below).

\subsection{Verification phase}

Whatever the proteomic platform approach used, hundreds to thousands of biomarker candidates can be generated but few of them may warrant assessment in a time-consuming and costly largescale clinical validation trial (Fig. 1). In a biomarker development pipeline, experimental design, prioritization, and verification are crucial early stages in the selection of the most promising candidates for clinical validation and translation to a specific clinical application $[39,40]$.

A better understanding of the disease state and the putative proteins or pathways involved in the process, taking into account their functional relevance to the cell/tissue or biofluid where they were identified as altered during the discovery phase, would help to develop meaningful criteria for prioritizing candidates for the further validation stage $[26,40]$. Methods based on immunoaffinity such as western blotting, ELISA, immunocyto/histochemistry, and more recently, SRM-based methods are the most popular in the verification stage (also referred to as assessment of performance when any candidates are verified by an orthogonal method, ie, other than that one used in the discovery phase) (Fig. 1). The relevance of the verification stage is reflected by the fact that for many proteomics journals of high impact, it is a mandatory requirement for reporting of clinical biomarker studies.

To help improve the overall success of the biomarker discovery pipeline, an important statistical framework for the design of biomarker discovery and verification studies was recently generated from the workshop entitled "Experimental Design Considerations in Research Studies Using Proteomic Technologies" with the participation of U.S. Food and Drug Administration (FDA) [41]. The ultimate goal of this statistical approach is to set clinical relevance and appropriate biospecimen sample size for discovery and verification stages prior to the clinical validation stage, contributing to making protein biomarker discovery from the bench to the clinic quicker and more successful. However, there is still a need for computational methods and algorithms allowing for consistent analysis and interpretation of proteomic data using statistical principles.

\subsection{Mass spectrometry}

Mass spectrometry measures the mass-to-charge ratio $(\mathrm{m} / \mathrm{z})$ of ionized molecules such as proteins/peptides and produces spectra containing $\mathrm{m} / \mathrm{z}$ values versus intensity count. Matrix-assisted laser desorption/ionization (MALDI) and Electrospray ionization (ESI) are the two most common techniques to volatize and ionize the proteins or peptides for subsequent mass spectrometric analysis. MALDIMS is mostly used to analyze relatively simple peptide mixtures (eg, from 2-D gel protein spots). Samples are deposited on a MALDI plate, left to dry with a crystalline matrix to be ionized via laser pulses. ESI ionizes the analytes out of a solution coming from an LC system. Integrated LC systems with ESI-MS systems (LC-MS) are preferentially used for analysis of complex samples. There are different types of mass analyzers, with different advantages/disadvantages, such as time-of-flight (TOF), ion trap, quadrupole, Fourier transform ion cyclotron (FT-MS), and orbitrap [42].

Fig. 2 outlines a frequently used strategy (bottom-up proteomics) for identifying potential novel biomarkers. The tryptic peptides generated from protein digestion are separated by LC and online injected into the mass spectrometer, which employs two stages of mass analysis (tandem MS) to identify peptides used subsequently to infer protein identification. Peptide sequencing is achieved by matching the tandem mass spectra derived with theoretical tandem mass
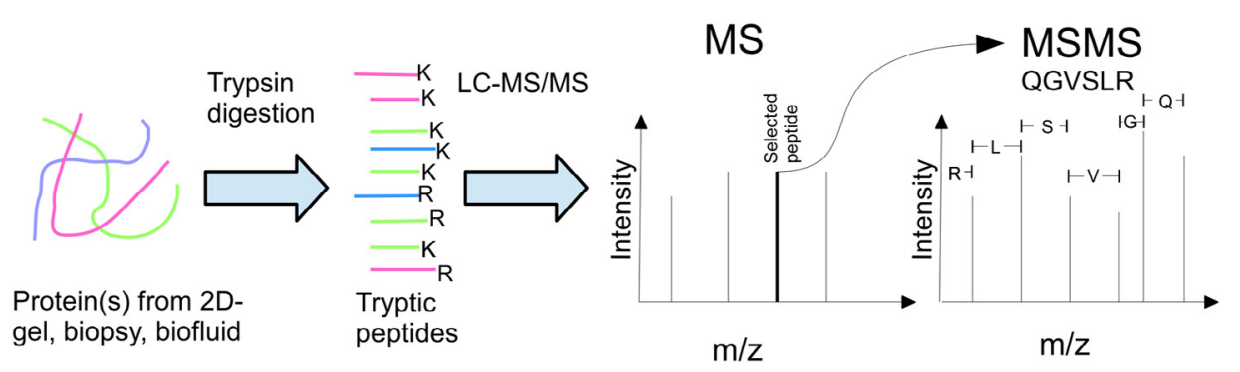

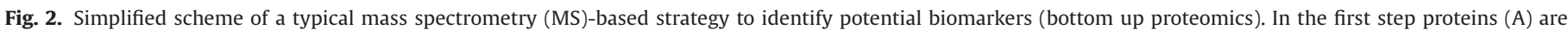

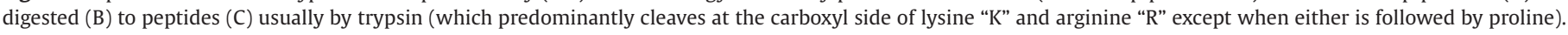

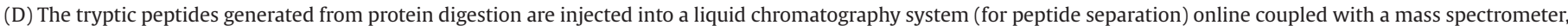

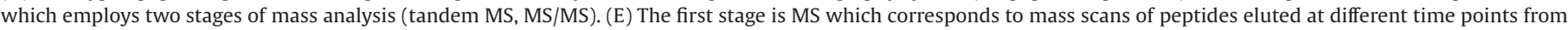

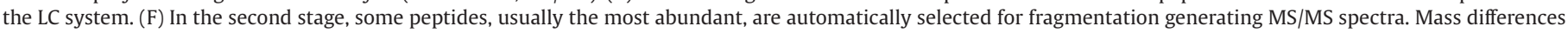

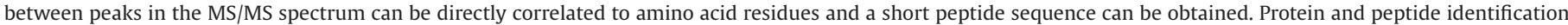

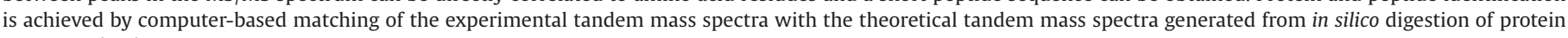
sequence databases. 


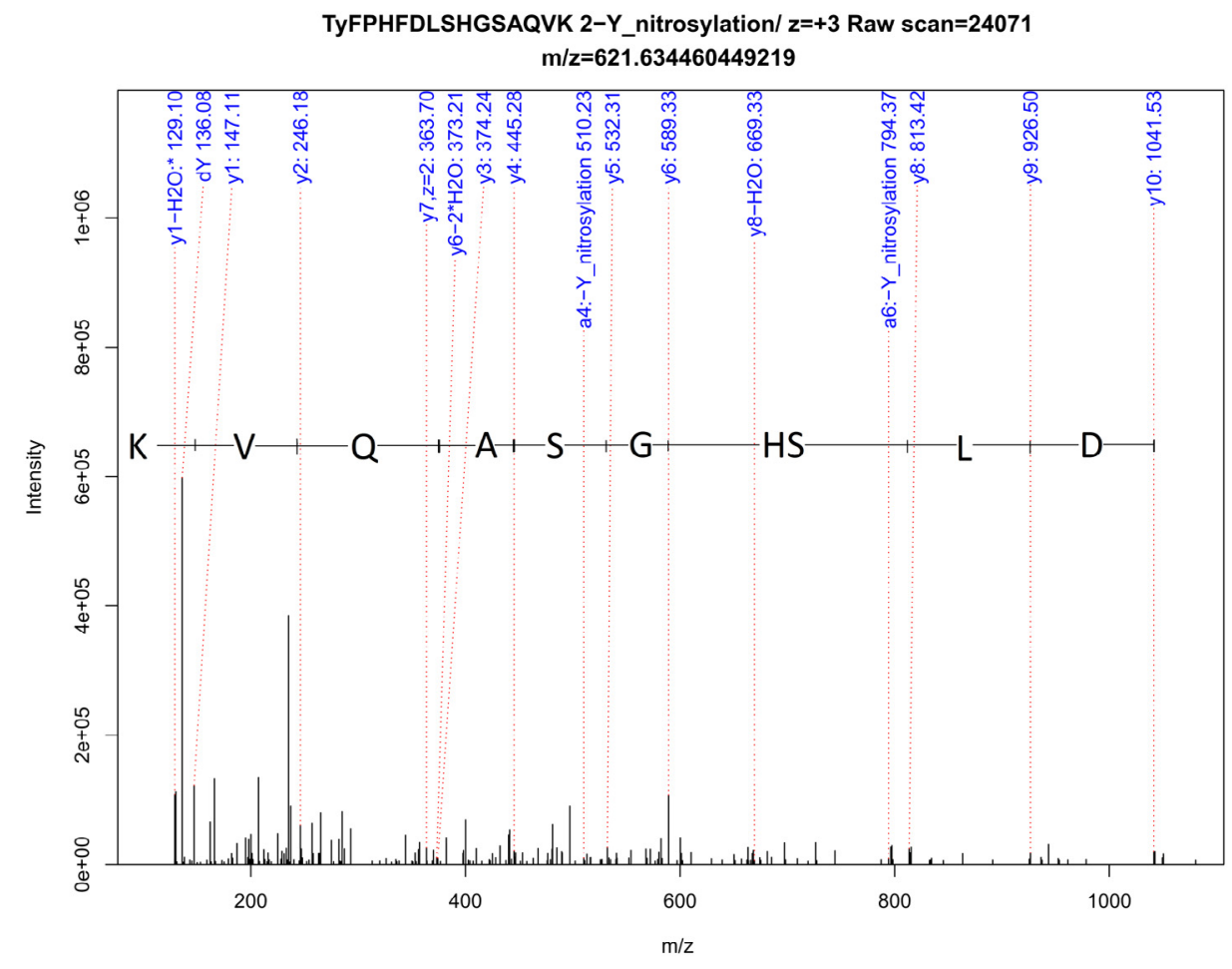

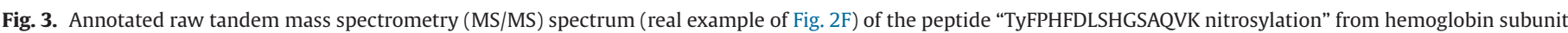

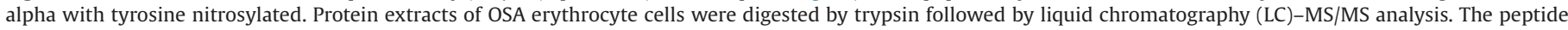

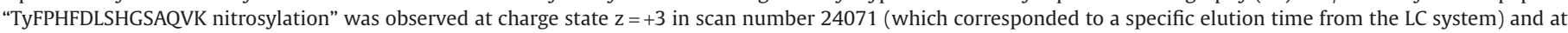

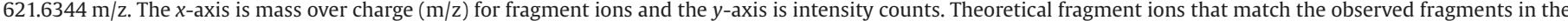

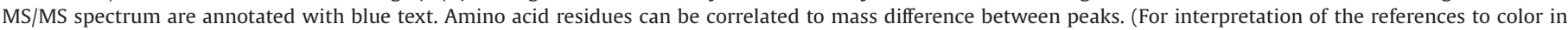
this figure legend, the reader is referred to the web version of this article.)

spectra generated from in silico digestion of a protein sequence database (Fig. 2). Protein inference is often complicated by the fact that many tryptic peptides are shared among proteins. Moreover, mass accuracy used for database-dependent search, the specific sequence database used for the search, the filtering criteria such as minimum number of peptides identified, and False Discovery Rate (FDR) cutoff can also dramatically change the proteins and peptides identified in the final report and can be a reason for lost information and low reproducibility when validation is performed in another laboratory that uses a different data analysis pipeline $[43,44]$. Besides protein inference, the protein state is another issue in bottom-up proteomics, which often does not provide accurate information on the site location of PTMs, and even if the site location is well determined the quantitative value cannot be directly linked to quantitative values of protein states [45]. Based on literature and our preliminary data, we hypothesize that specific PTMs could be involved or linked to OSA. We already identified several oxidation and nitrosylation products that, in general, display a regulatory difference between snorers and OSA patient groups. An example of a nitrosylated peptide from hemoglobin subunit alpha identified by MS/MS is provided in Fig. 3. This was accomplished by using state-of-the-art mass spectrometers and by using an open search for modifications when matching MS/MS spectra against sequence databases [46-48].

\section{Proteomics in obstructive sleep apnea syndrome}

Pathophysiological mechanisms underlying OSA are still elusive. Researchers endeavor to understand why patients with similar severity of OSA often have significantly different clinical manifestations and co-morbidities. Which mechanisms distinguish OSA in the pediatric and adult populations? How should the adequacy of treatment response be monitored? Studies on sleep deprivation in animal models [49-51] and OSA syndrome in human cohorts using proteomics approaches imply the great potential of this emerging discipline to impose scientific dilemmas of etiology, diagnosis, and treatment of OSA. Herein, we review the proteomics studies performed so far in children (Table 1) and adult (Table 2) populations, in an attempt to discover biomarkers for improving diagnosis, treatment, and a better understanding of OSA pathology.

Shih and Malhotra identified properties of an ideal biomarker for OSA, which should be highly sensitive, specific, dose-responsive, and correlate with the severity of the disease. The biomarker or set of biomarkers should serve as a measure of adequacy of therapy and be involved in the causal pathway, therefore being useful for predicting outcome $[63,64]$.

The pioneering work of Shah et al. (2006) on serum proteome profiling in pediatric OSA patients is in concordance with criteria for an ideal OSA biomarker [52]. They identified three differently expressed proteins which could distinguish OSA versus OSA-free patients with $93 \%$ sensitivity and $90 \%$ of specificity [52] (Table 1). In this study the SELDI-TOF MS approach was used for analysis. After MS analysis, proprietary classification algorithms were applied, involving three nodes with distinct masses. Three discriminatory peaks of 5896, 3306, 6068 Da distinguished OSA from controls with 93\% sensitivity and $90 \%$ specificity. A protein biomarker candidate corresponding to a peak at 5896 Da was identified as osteocalcin [52] (Table 1). Increased serum osteocalcin was previously observed in diseases with increased bone turnover and in children with growth retardation. Since growth retardation is a frequent observation in children with OSA, authors suggested that the increase of osteocalcin in these patients may compensate for the growth deceleration imposed by the episodic asphyxic events associated with recurrent upper-airway obstruction [52]. 
Table 1

Proteomics studies conducted in children with obstructive sleep apnea (OSA).

\begin{tabular}{|c|c|c|c|c|}
\hline Reference & Proteomics approach & Sample & Main findings & Orthogonal verification \\
\hline Shah et al. [52] & SELDI-TOF & $\begin{array}{l}\text { Children/serum } \\
\text { (20 OSA/20 controls) }\end{array}$ & $\begin{array}{l}\uparrow 3 \text { protein peaks }(5896,3306,6068 \mathrm{Da}) \text { with } \\
93 \% \text { sensitivity/90\% specificity } \\
\text { Peak } 5896 \text { Da identified as osteocalcin }\end{array}$ & No \\
\hline Krishna et al. [53] & 2D-PAGE/MALDI/TOF/TOF & $\begin{array}{l}\text { Children/urine } \\
\text { (11 OSA/11 controls) }\end{array}$ & $\begin{array}{l}\uparrow \text { Gelsolin, perlecan, albumin, tropomyosin and } \\
\text { immunoglobulin }\end{array}$ & No \\
\hline Gozal et al. [54] & 2D-DIGE & $\begin{array}{l}\text { Children/urine } \\
\text { (60 OSA/60 controls) }\end{array}$ & $\begin{array}{l}12 \text { proteins identified modulated } \\
\uparrow \text { Uromodulin, urocortin- } 3 \text {, orosomucoid- } 1 \text { and } \\
\downarrow \text { kallikrein with high sensitivity/specificity in } \\
\text { ROC analysis }\end{array}$ & $\begin{array}{l}\text { ELISA ( } \uparrow \text { kallikrein, uromodulin and } \\
\text { urocortin- } 3 \text { ) } \\
\text { WB }(\uparrow \text { tenascin, tribbles homolog- } 2 \text { and } \\
\downarrow \text { zinc finger protein } 81)\end{array}$ \\
\hline Snow et al. [55] & SELDI-TOF & $\begin{array}{l}\text { Children/urine } \\
\text { (30 OSA/25 controls) }\end{array}$ & 个Urocortins & No \\
\hline
\end{tabular}

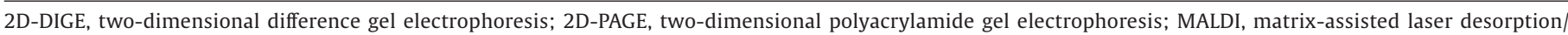
ionization; SELDI, surface enhancer laser desorption ionization; TOF, time of flight.

Table 2

Proteomics studies conducted in adults with obstructive sleep apnea (OSA).

\begin{tabular}{|c|c|c|c|c|}
\hline Reference & Proteomics approach & Sample & Main findings & Orthogonal verification \\
\hline Kim et al. [56] & $\begin{array}{l}\text { 2D-PAGE (silver staining)/ } \\
\text { MALDI/TOF/TOF }\end{array}$ & $\begin{array}{l}\text { Adults/serum depleted } \\
\text { for albumin and IgG } \\
\text { (40 OSA/34 controls) }\end{array}$ & $\begin{array}{l}\uparrow \text { Haptoglobin, apolipoprotein } \mathrm{M} \text { (apoM) and four } \\
\text { complement components, } \downarrow \text { paraoxonase- } 1 \text { (PNO1) } \\
\text { and } \alpha \text {-ferrous-carbonmonoxy }\end{array}$ & $\begin{array}{l}\text { WB ( } \uparrow \text { haptoglobin, apoN } \\
\text { and } \downarrow \text { PNO1) haptoglobin } \\
\text { decreased after CPAP }\end{array}$ \\
\hline Jurado Gámez et al. [57] & $\begin{array}{l}\text { 2D-PAGE (sypro-ruby } \\
\text { staining) }\end{array}$ & $\begin{array}{l}\text { Adults/serum depleted by } \\
\text { Proteominer kit ( } 24 \text { OSA } 8 \\
\text { controls) }\end{array}$ & $\begin{array}{l}10 \text { spot proteins modulated }(3 \uparrow \text { and } 7 \downarrow) \\
\text { No MS identification }\end{array}$ & No \\
\hline Jurado Gámez et al. [58] & iTRAQ/MALDI/TOF/TOF & $\begin{array}{l}\text { Adults/sera ( } 30 \text { OSA } \\
\text { mild/moderate/severe/ } 10 \\
\text { controls) }\end{array}$ & $\begin{array}{l}30 \text { proteins identified modulated ( } 19 \uparrow \text { and } 11 \downarrow \text { ) } \\
\downarrow C 4 \text { BPalpha and thrombospondim in all three OSA } \\
\text { groups; } \downarrow \text { vitronectinm clusterin isoform } 2 \text {, ApoE and } \\
\text { antithrombin in mild and moderate OSA } \\
13 \uparrow \text { in mild, } 7 \uparrow \text { in moderate and } 5 \uparrow \text { in severe OSA. } \\
\text { Alterations in lipidic and vascular and metabolic } \\
\text { pathways are particularly involved }\end{array}$ & No \\
\hline Jurado Gámez et al. [59] & iTRAQ/MALDI/TOF/TOF & $\begin{array}{l}\text { Adults/sera } \\
\text { (11 OSA/11 controls) }\end{array}$ & $\begin{array}{l}\text { } P R O 0684 \text {, short immunoglobulin lambda VLJ and } \\
\text { kininogen HMW precursor involved in } \\
\text { inflammation, immune response and coagulation }\end{array}$ & No \\
\hline Jurado Gámez B et al. [60] & $\begin{array}{l}\text { 2D-PAGE (sypro-ruby } \\
\text { staining)/MALDI/TOF/TOF }\end{array}$ & $\begin{array}{l}\text { Adults/sera } \\
\text { (37 OSA/18 controls) }\end{array}$ & $\begin{array}{l}\uparrow \text { Haptoglobin } \\
\downarrow \downarrow \text { Albumin and serotransferrin }\end{array}$ & No \\
\hline Shinohara et al. [61] & $\begin{array}{l}\text { LC/MS/MS (LTQ } \\
\text { instrument) }\end{array}$ & $\begin{array}{l}\text { Adults/plasma ( } 6 \text { severe } \\
\text { obese OSA/ } 6 \text { controls } \\
\text { non-obese) }\end{array}$ & $\begin{array}{l}26 \text { proteins modulated ( } 12 \uparrow \text { and } 14 \downarrow) \\
\uparrow \text { Complement proteins, ceruloplasmin, amyloid } \\
\text { P-component associated with inflammation and } \\
\text { immunomodulation }\end{array}$ & No \\
\hline Seetho et al. [62] & CE-MS & $\begin{array}{l}\text { Adults/urine ( } 61 \text { obese } \\
\text { OSA/31 obese non-OSA) }\end{array}$ & $\begin{array}{l}24 \text { peptides (some of these generated from collagens } \\
\text { and fibrinogen alfa) were candidates for differential } \\
\text { distribution }\end{array}$ & No \\
\hline
\end{tabular}

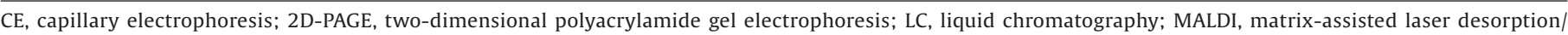
ionization; MS, mass spectrometry; TOF, time of flight.

Searching for a non-invasive biomarker test for OSA, Krishna et al. have used urine as a source for identifying new biomarkers [53]. They performed a study in a pediatric population with a mean age of 6.8 years. The discrimination criterion for stratification in the OSA/ non-OSA group was AHI (AHI $<1 / \mathrm{h}$ - control; AHI $>5 / \mathrm{h}-$ OSA group). For proteomics analysis 2D-PAGE and the MALDI-TOF-TOF MS approach was used. After an image analysis of 22 urine samples, five spots were selected for further analysis based on intensity differences between two examined groups. Authors pin-pointed five identified proteins $(\mathrm{p}<0.05$, protein score $>67)$ : gelsolin, percolan, albumin, tropomyosin, and immunoglobulin. Krishna and coauthors found a subset of proteins that markedly have different expression in the urine of pediatric patients with sleep-disordered breathing. Based on these results, the authors suggested the renal system as another end-organ target for OSA. Validation of these finding as well as future prospective studies on larger cohorts is required to confirm their findings [53].

Gozal et al. also conducted extensive 2D-DIGEs and MALDI-TOFTOF MS studies of urinary proteome aiming to extend their preliminary findings in pediatric OSA [54]. The authors performed extensive 2D-DIGE experiments, 150 in total, to ascertain reproducibility and consistency of results. The total number of detectable protein spots ranged from 713 to 789 in all urine samples, of which 23 were markedly differently expressed across all gels. About 12 novel non-redundant proteins were identified with a high level of confidence. Image analysis showed that three of the identified proteins were under-expressed while nine were overexpressed in OSA patients. Six of these 12 identified candidate biomarkers were validated by ELISA (Kallikrein, uromodulin, urocortin-3) and western blotting (tenascin, tribbles homolog-2, zinc finger protein 81). ROC analysis performed for uromodulin, urocortin-3, orosomucoid-1, and kallikrein shows high sensitivity and specificity in the identification of OSA. The authors suggested future larger prospective studies to validate the abovementioned findings.

Snow and collaborators used SELDI-TOF MS to profile proteins in the first morning void urines from children with OSA [55] and habitual snorers. Using the supervised linear discriminative analysis of the normalized peaks obtained from urine protein profiling, two distinct proteins among the OSA group were discovered, characterized by molecular weights of $4382 \mathrm{Da}$ and $4640 \mathrm{Da}$. The most plausible and relevant preliminary identification of the putative biomarker pointed toward urocortin (UCN), which is the prototype 
of an important family - the corticotrophin-releasing hormonerelated peptides which mediate response to stress as well as stresscoping processes.

According to our knowledge, Kim and co-workers have been the first to analyze serum proteome of OSA adult subjects [56]. Criteria of OSA severity were based on AHI and co-related clinical symptoms. After 3-5 months on CPAP therapy, the serum of 10 subjects of OSA and controls was subjected to proteomics analysis. Differently expressed proteins were detected after previous separation of samples using silver-stained 2D-PAGE, followed by image analysis. Protein abundance per spot was elucidated by integrating pixel densities and correcting for the background. Spots which showed equal or higher than two-fold alteration in protein expression were considered for further MS analysis. In total, nine spots were found to be markedly up- or down-regulated in patients with OSA (Table 2). After excision, these protein spots were analyzed by MALDI-TOFTOF MS, and identified using ProFound program. Except serum paraoxonase (PON1) and alpha-ferrous-carbonmonoxy, all identified proteins were highly abundant. These findings were validated by western blotting and ELISA techniques for the haptogolobin, PON1, and apo $\mathrm{M}$ [56]. It is important to note that levels of haptoglobin were significantly higher in all patients with OSA. However, after CPAP treatment the level of haptoglobin was markedly decreased. This finding implies haptoglobin as a putative serum biomarker for the follow up CPAP treatment in OSA patients. This behavior was not followed by the other two validated proteins. Haptoglobin and apo M were found to be independently associated with AHI [56].

Jurado Gámez et al., in 2010, applied sypro-ruby-stained 2DPAGE for the analysis of serum protein signature of patients with different stages of OSA syndrome [57]. Patients were stratified by AHI into four groups - controls and mild, moderate, and severe OSA, each constituted by eight individuals. After image analysis, optical density of the protein spots which were three-fold changed compared to corresponding spots in control samples were considered as putative biomarkers. In total 10 protein spots met this criteria, of which three were overexpressed, while seven were underexpressed compared to controls. Although, none of these spots were further identified by MS, this preliminary work showed for the first time that distinct levels of a group of proteins can correlate with the severity of OSA. From this preliminary study, the authors moved on to apply a more powerful technique, iTRAQ isobaric tags associated with MALDI-TOF-TOF, aiming to obtain deeper knowledge and identify differently expressed proteins [58]. Researchers conducted a prospective observational study designed as described earlier [57]. To minimize any variance in findings, this study included only males referred to the Sleep Unit. Subjects were assigned into groups according to AHI: controls and mild, moderate, and severe OSA patients. Morning serum was collected and pooled according to OSA severity and control groups using equimolar protein contributions from each subject. Samples were prepared for proteomic analysis [58], labeled with iTRAQ4plex tagging kit, and analyzed by MALDI-TOF-TOF MS. Database searches (Protein Pilot) resulted in identification of 103 proteins of which 30 showed differences in expression between OSA and control groups (11 underand 19 over-expressed) (Table 2). The authors highlighted that complement component 4-binding alpha and thrombospondin precursor proteins were significantly under-expressed in all OSA groups, while the rest of the underexpressed proteins were only assigned to the groups with mild and moderate OSA when compared to control. Among the overexpressed proteins it should be emphasized that fibronectin, Apo B100, immunoglobulin heavy constant alpha 1, and Apo D showed progressive severity-related ratio increases in OSA groups compared to control. Cellular fibronectin may be a protein marker for the activation of endothelial cells. Elevated ApoB-100 is associated with an increased risk of cardiovascular disease. Ceruloplasmin interacts with other proteins in the inflammatory pathways. Although, none of these proteins were verified by orthogonal techniques, the authors suggested that these sets of modulated proteins can be potentially related to several metabolic pathways, such as the lipid and vascular metabolic pathways, suggesting that OSA may facilitate the onset and progression of atherogenesis. A number of proteins involved in coagulation, inflammation, and lipid metabolism may indeed interact in the context of OSA to affect lipid and vascular pathways. Jurado Gámez and collaborators concluded that protein expression correlates with severity of disease, but at the same time provides relevant mechanistic information.

Further, Jurado Gámez et al. designed a prospective pilot study aiming to identify differences in protein expression in patients with mild OSA syndrome [59]. Morning serum of individuals was acquired and processed for proteomic analysis. Peptide tryptic digests were labeled with isobaric tags (ITRAQ) and submitted to analysis by MALDI-TOF-TOF MS using ProteinPilot software for peptide identification. Proteins which had iTRAQ ratio $>1.3$ related to control, were considered as overexpressed and three proteins fulfilled this criterion: PRO0684, short immunoglobulin lambda VLJ, and kininogen HMW precursor. However, these results are preliminary and not validated by orthogonal techniques. Further study in a bigger cohort without gender discrimination is needed to confirm these findings.

Jurado-Gámez et al. designed another prospective study using 2-PAGE to identify differentially expressed proteins in an OSA population with an age range between 30 and 70 years [60]. They identified haptoglobin as overexpressed in OSA. Haptoglobin has been associated with cardiovascular risk in patients with OSA [65]. Two under-expressed spots were identified as albumin and serotransferrin, suggesting that these proteins can facilitate a decrease of the antioxidant defenses in OSA. Albumin is the most abundant protein in the circulatory system. Low abundance of serum albumin can be related with high levels of urinary albumin excretion observed in OSA patients, even in the absence of associated hypertension or diabetes [66]. Albumin has an antioxidative activity due to its capacity to bind ions and to eliminate free radicals [67]. Serotransferrin is a glycoprotein produced and metabolized in hepatocytes and the main function is iron transport in blood allowing an antioxidant capacity [60].

Shinohara and co-workers examined plasma proteomic profiling in severe OSA patients with obesity $\left(B M I>30 \mathrm{~kg} / \mathrm{m}^{2}\right)$ and nonOSA patients without obesity $\left(\mathrm{BMI}<30 \mathrm{~kg} / \mathrm{m}^{2}\right)$ [61]. In this work, the shotgun approach was used in protein analysis. A total of 19,745 components were tracked and differentially quantified. Many proteins regarding inflammation and immune response, including complement proteins, two acute-phase reactants ceruloplasmin and serum amyloid P-component, were found to be highly expressed in obese severe OSA patients (Table 2). The authors concluded that protein changes responsible for immune modulation and inflammation may be a feature of OSA patients. The authors acknowledged limitations of the study due to small sample size. However, they highlighted findings of the study, which revealed that a high percentage of differently expressed proteins are associated with modulation of immune system and inflammation, thus suggesting that these mechanisms are involved in OSA syndrome. Further verification and validation of these findings will be necessary to confirm their participation in the pathophysiology of OSA.

During revision of this manuscript we came across the work of Seetho et al. reporting urinary proteomics profiling in OSA and nonOSA obese adult patients using CE-MS technology [62]. The data showed 24 peptides that were differentially abundant $(\mathrm{p}<0.01)$ between patient groups, although these differences did not reach significance after adjustment for multiple statistical testing to account for false positives (false discovery rate). Some of these peptides originated from collagens and fibrinogen alpha. No further verification experiments were performed. 


\section{Conclusion}

Heterogeneous studies in sampling, relatively small cohorts, nonstandardized diagnostic methods, lack of verification and validation data are the main drawback of proteomics studies made to date in OSA patients. At this stage, these studies should be considered very preliminary. Nevertheless, the results obtained so far are tremendously encouraging for showing significant differences in OSA proteome profile which, once validated, may be considered for translation into a proteomics-based noninvasive testing for OSA screening, diagnosis, or prognosis. These first studies opened new perspectives for future proteomic evaluation in OSA patients, orienting the design of future proteomics studies. Those should be undertaken as much as possible in bigger cohorts of adults/children with OSA presenting different levels of severity and co-morbidities. Proteomics analysis in different biological samples (other than serum or urine), such as plasma, blood cells (eg, red blood cells, macrophages) or even nasal epithelia, should also be considered in future studies. In terms of proteomic technology, the application of complementary approaches such as 2D-DIGE with higher-throughput technologies such as LC-MS/MS using a new generation of mass spectrometers (eg, orbitrap system) and/or a target proteomics approach (SRM assay) will certainly increase markedly the sensitivity/ specificity for biomarker identification in OSA. A verification step using orthogonal technologies should always be considered as a crucial step to better select the most promising candidates for further clinical trial validation. Since OSA is a disorder occurring during sleep time, evaluating proteomic signature before, during, and after sleep in persons with and without CPAP therapy could give an answer regarding molecular pathways and metabolic alterations in persons with OSA. Such changes will be at least partly a consequence of chronic intermittent hypoxia and sleep fragmentation that occur during the sleep.

In summary, much investigation remains to be done before we can define potential biomarkers for OSA with impact on diagnosis, disease management, and prognosis of this prevalent disorder. Research efforts could then be directed at identifying novel treatment interventions that not only modify the biomarker levels but also affect the pathophysiology of the disease and its clinical outcome.

\section{Conflict of interest}

The authors have declared no conflict of interest.

The ICMJE Uniform Disclosure Form for Potential Conflicts of Interest associated with this article can be viewed by clicking on the following link: http://dx.doi.org/10.1016/j.sleep.2014.11.014.

\section{Acknowledgements}

Work partially supported by Harvard Medical School - Portugal Program (HMSP-ICJ/0022/2011), Fundação para a Ciência e a Tecnologia (FCT)/Poly-Annual Funding Program and FEDER/Saúde XXI Program (Portugal) and postdoctoral FCT-fellowship (SFRH/BPD/43365/2008).

\section{References}

[1] Yim S, Jordan A, Malhotra A. Obstructive sleep apnea: clinical presentation, diagnosis and treatment. In: Randerath WJ, Sanner BM, Somers VK, editors. Sleep apnea current diagnosis and treatment. Basel: Karger; 2006. p. 118-36.

[2] Caples SM, Gami AS, Somers VK. Obstructive sleep apnea. Ann Intern Med 2005;142:187-97.

[3] Pack AI. Advances in sleep-disordered breathing. Am J Respir Crit Care Med 2006;173:7-15.

[4] McNicholas WT, Bonsigore MR, Management Committee of ECAB. Sleep apnoea as an independent risk factor for cardiovascular disease: current evidence, basic mechanisms and research priorities. Eur Respir J 2007;29:156-78.
[5] Lurie A. Obstructive sleep apnea in adults: epidemiology, clinical presentation, and treatment options. Adv Cardiol 2011;46:1-42.

[6] Lumeng JC, Chervin RD. Epidemiology of pediatric obstructive sleep apnea. Proc Am Thorac Soc 2008;5:242-52.

[7] Attal P, Chanson P. Endocrine aspects of obstructive sleep apnea. J Clin Endocrinol Metab 2010;95:483-95.

[8] Lin QC, Zhang XB, Chen GP, Huang DY, Din HB, Tang AZ. Obstructive sleep apnea syndrome is associated with some components of metabolic syndrome in nonobese adults. Sleep Breath 2012;16:571-8.

[9] Schmid SM, Hallschmid M, Schultes B. The metabolic burden of sleep loss. Lancet Diabetes Endocrinol 2014;3:52-62.

[10] Coughlin SR, Mawdsley L, Mugarza JA, Calverley PM, Wilding JP. Obstructive sleep apnoea is independently associated with an increased prevalence of metabolic syndrome. Eur Heart J 2004;25:735-41.

[11] Madani M, Madani F. Epidemiology, pathophysiology, and clinical features of obstructive sleep apnea. Oral Maxillofac Surg Clin North Am 2009;21:369_ 75.

[12] Health Quality Ontario. Polysomnography in patients with obstructive sleep apnea: an evidence-based analysis. Ont Health Technol Assess Series 2006;6:138.

[13] Whittle AT, Finch SP, Mortimore IL, MacKay TW, Douglas NJ. Use of home sleep studies for diagnosis of the sleep apnoea/hypopnoea syndrome. Thorax 1997:52:1068-73.

[14] Berry RB, Budhiraja R, Gottlieb DJ, et al Rules for scoring respiratory events in sleep: update of the 2007 AASM Manual for the Scoring of Sleep and Associated Events. Deliberations of the sleep apnea definitions task force of the American Academy of Sleep Medicine. J Clin Sleep Med 2012;8:597-619.

[15] Bahammam AS, Obeidat A, Barataman K, Bahammam SA, Olaish AH, Sharif MM. A comparison between the AASM 2012 and 2007 definitions for detecting hypopnea. Sleep Breath 2014;18:767-73.

[16] Guilleminault C, Hagen CC, Huynh NT. Comparison of hypopnea definitions in lean patients with known obstructive sleep apnea hypopnea syndrome (OSAHS). Sleep Breath 2009;13:341-7.

[17] Knapp A, Myhill PC, Davis WA, et al Effect of continuous positive airway pressure therapy on sexual function and serum testosterone in males with type 2 diabetes and obstructive sleep apnoea. Clin Endocrinol (Oxf) 2014;81:254-8.

[18] Sanchez AI, Martinez P, Miro E, Bardwell WA, Buela-Casal G. CPAP and behavioral therapies in patients with obstructive sleep apnea: effects on daytime sleepiness, mood, and cognitive function. Sleep Med Rev 2009;13:223-33.

[19] Ballard RD. Management of patients with obstructive sleep apnea. J Fam Pract 2008;57:S24-30.

[20] Stasche N. Selective indication for positive airway pressure (PAP) in sleep-related breathing disorders with obstruction. GMS Curr Top Otorhinolaryngol Head Neck Surg 2006;5:Doc06.

[21] Tan HL, Kheirandish-Gozal L, Gozal D. The promise of translational and personalised approaches for paediatric obstructive sleep apnoea: an 'Omics' perspective. Thorax 2014;69:474-80.

[22] Smith LM, Kelleher NL, Consortium for Top Down P. Proteoform: a single term describing protein complexity. Nat Methods 2013;10:186-7.

[23] Anderson NL, Matheson AD, Steiner S. Proteomics: applications in basic and applied biology. Curr Opin Biotechnol 2000;11:408-12.

[24] Mayr M, Zhang J, Greene AS, Gutterman D, Perloff J, Ping P. Proteomics-based development of biomarkers in cardiovascular disease: mechanistic, clinical, and therapeutic insights. Mol Cell Proteomics 2006;5:1853-64.

[25] Simões T, Charro N, Alexandre BM, Penque D. Proteomics in detection and monitoring chronic lung diseases: the human nasal epithelium as a molecular model. J Allergy Ther 2012;:S7:004. OMICS Group.

[26] O’Neil SE, Palviainen MJ, Ten Have S, et al Clinical proteomics stretch goals: EuPA 2012 roundtable report. J Proteomics 2013;88:37-40.

[27] Anderson NL, Anderson NG. The human plasma proteome: history, character, and diagnostic prospects. Mol Cell Proteomics 2002;1:845-67.

[28] Zhang Y, Fonslow BR, Shan B, Baek MC, Yates JR. 3rd Protein analysis by shotgun/bottom-up proteomics. Chem Rev 2013;113:2343-94.

[29] Unlu M, Morgan ME, Minden JS. Difference gel electrophoresis: a single gel method for detecting changes in protein extracts. Electrophoresis 1997; 18:2071-7.

[30] Penque D. Two-dimensional gel electrophoresis and mass spectrometry for biomarker discovery. PROTEOMICS Clin Appl 2009;3:155-72.

[31] Megger DA, Bracht T, Meyer HE, Sitek B. Label-free quantification in clinical proteomics. Biochim Biophys Acta 2013;1834:1581-90.

[32] Liu H, Sadygov RG, Yates JR. 3rd A model for random sampling and estimation of relative protein abundance in shotgun proteomics. Anal Chem 2004;76:4193-201.

[33] Wu WW, Wang G, Baek SJ, Shen RF. Comparative study of three proteomic quantitative methods, DIGE, cICAT, and ITRAQ, using 2D gel- or LC-MALDI TOF/TOF. J Proteome Res 2006;5:651-8.

[34] Peng J, Stanley AJ, Cairns D, Selby PJ, Banks RE. Using the protein chip interface with quadrupole time-of-flight mass spectrometry to directly identify peaks in SELDI profiles-initial evaluation using low molecular weight serum peaks. Proteomics 2009;9:492-8.

[35] Mischak H, Coon JJ, Novak J, Weissinger EM, Schanstra JP, Dominiczak AF. Capillary electrophoresis-mass spectrometry as a powerful tool in biomarker discovery and clinical diagnosis: an update of recent developments. Mass Spectrom Rev 2009;28:703-24.

[36] Anderson L, Hunter CL. Quantitative mass spectrometric multiple reaction monitoring assays for major plasma proteins. Mol Cell Proteomics 2006;5:573-88. 
[37] Picotti P, Aebersold R. Selected reaction monitoring-based proteomics: workflows, potential, pitfalls and future directions. Nat Methods 2012;9:555-66.

[38] Liebler DC, Zimmerman LJ. Targeted quantitation of proteins by mass spectrometry. Biochemistry 2013;52:3797-806.

[39] Rifai N, Gillette MA, Carr SA. Protein biomarker discovery and validation: the long and uncertain path to clinical utility. Nat Biotechnol 2006;24:971-83.

[40] Paulovich AG, Whiteaker JR, Hoofnagle AN, Wang P. The interface between biomarker discovery and clinical validation: the tar pit of the protein biomarker pipeline. PROTEOMICS Clin Appl 2008;2:1386-402.

[41] Skates SJ, Gillette MA, LaBaer J, et al Statistical design for biospecimen cohort size in proteomics-based biomarker discovery and verification studies. J Proteome Res 2013;12:5383-94.

[42] Aebersold R, Mann M. Mass spectrometry-based proteomics. Nature 2003;422:198-207.

[43] Matthiesen R, Bunkenborg J. Introduction to mass spectrometry-based proteomics. Methods Mol Biol 2013;1007:1-45.

[44] Matthiesen R, Prieto G, Amorim A, et al SIR: deterministic protein inference from peptides assigned to MS data. J Proteomics 2012;75:4176-83.

[45] Matthiesen R, Azevedo L, Amorim A, Carvalho AS. Discussion on common data analysis strategies used in MS-based proteomics. Proteomics 2011;11:604-19.

[46] Carvalho AS, Ribeiro H, Voabil P, et al Global mass spectrometry and transcriptomics array based drug profiling provides novel insight into glucosamine induced ER stress. Mol Cell Proteomics 2014;13:3294-307.

[47] Matthiesen R, Carvalho AS. Methods and algorithms for quantitative proteomics by mass spectrometry. Methods Mol Biol 2013;1007:183-217.

[48] Matthiesen R. Algorithms for database-dependent search of MS/MS data. Methods Mol Biol 2013;1007:119-38.

[49] Row BW, Goldbart A, Gozal E, Gozal D. Spatial pre-training attenuates hippocampal impairments in rats exposed to intermittent hypoxia. Neurosci Lett 2003;339:67-71.

[50] Row BW, Liu R, Xu W, Kheirandish L, Gozal D. Intermittent hypoxia is associated with oxidative stress and spatial learning deficits in the rat. Am J Respir Crit Care Med 2003;167:1548-53.

[51] Basheer R, Brown R, Ramesh V, Begum S, McCarley RW. Sleep deprivationinduced protein changes in basal forebrain: implications for synaptic plasticity. J Neurosci Res 2005;82:650-8.

[52] Shah ZA, Jortani SA, Tauman R, Valdes R. Jr, Gozal D. Serum proteomic patterns associated with sleep-disordered breathing in children. Pediatr Res 2006;59:466-70.
[53] Krishna J, Shah ZA, Merchant M, Klein JB, Gozal D. Urinary protein expression patterns in children with sleep-disordered breathing: preliminary findings. Sleep Med 2006; 7:221-7.

[54] Gozal D, Jortani S, Snow AB, et al Two-dimensional differential in-gel electrophoresis proteomic approaches reveal urine candidate biomarkers in pediatric obstructive sleep apnea. Am J Respir Crit Care Med 2009;180:1253-61.

[55] Snow A, Gozal D, Valdes R. Jr, Jortani SA. Urinary proteins for the diagnosis of obstructive sleep apnea syndrome. Methods Mol Biol 2010;641:223-41.

[56] Kim J, Lee S, In K, et al Increase in serum haptoglobin and apolipoprotein M in patients with obstructive sleep apnoea. J Sleep Res 2009;18:313-20.

[57] Jurado Gámez B, Gómez-Chaparro Moreno JL, Muñoz Calero M, et al Variación de la expresión proteica en función de la gravedad del síndrome de apneahipopnea del sueño. Arch Bronconeumol 2010;46:288-93.

[58] Jurado-Gamez B, Gomez-Chaparro JL, Munoz-Calero M, et al Serum proteomic changes in adults with obstructive sleep apnoea. J Sleep Res 2012;21:13946.

[59] Jurado Gámez B, Muñoz Calero M, García Porcuna I, et al Valoración de la sobreexpresión proteica en pacientes con SAHS leve. Rev Esp Patol Torác 2012;24:178-83.

[60] Jurado Gámez B, Arenas Delarriva MS, Muñoz Calero M, et al Papel de la proteómica en la identificación de proteínas diferenciales en pacientes con sahs. Rev Esp Patol Torác 2012;24:272-8.

[61] Shinohara M, Sakurai T, Sakao S, et al Plasma proteomic analysis in patients with obstructive sleep apnea syndrome. Sleep Biolog Rhythms 2012;10:336-9.

[62] Seetho IW, Siwy J, Albalat A, et al Urinary proteomics in obstructive sleep apnoea and obesity. Eur J Clin Invest 2014;44:1104-15.

[63] Shih JL, Malhotra A. Could vitamins be helpful to patients with sleep apnea? Chest 2011;139:237-8.

[64] Montesi SB, Bajwa EK, Malhotra A. Biomarkers of sleep apnea. Chest 2012;142:239-45

[65] Lavie L, Lotan R, Hochberg I, Herer P, Lavie P, Levy AP. Haptoglobin polymorphism is a risk factor for cardiovascular disease in patients with obstructive sleep apnea syndrome. Sleep 2003;26:592-5.

[66] Ursavas A, Karadag M, Gullulu M, et al Low-grade urinary albumin excretion in normotensive/non-diabetic obstructive sleep apnea patients. Sleep Breath 2008;12:217-22.

[67] Bourdon E, Blache D. The importance of proteins in defense against oxidation. Antioxid Redox Signal 2001;3:293-311. 